\title{
Movimento de imãs ao deslizar sobre um plano inclinado de alumínio
}

\author{
Magnet movement when sliding on an inclined aluminum plane \\ Francisco Catelli ${ }^{*}\left[\right.$, Andréa Cantarelli Morales ${ }^{10}$ \\ ${ }^{1}$ Universidade de Caxias do Sul, Caxias do Sul, RS, Brasil.
}

\begin{abstract}
Recebido em 11 de janeiro de 2021. Revisado em 04 de fevereiro de 2021. Aceito em 12 de fevereiro de 2021.
Uma variação da conhecida queda de um imã de neodímio - ferro - boro por dentro de um tubo de material condutor não magnético é apresentada nesse trabalho; o imã retirado de um mecanismo de movimento do braço de gravação e leitura de um disco rígido é colocado a deslizar por uma rampa de alumínio colocada próxima à vertical. Essa configuração possui a grande vantagem de poder ser vista por uma (eventualmente) grande audiência; adicionalmente, as transformações de energia são suficientemente simples para serem tratadas em cursos de física de nível médio. O tratamento dado a essa atividade didática, adequado ao nível médio de ensino de Física, ou mesmo ensino superior introdutório, envolve a exploração de princípios ligados à conservação de energia.
\end{abstract}

Palavras-chave: Correntes induzidas, Conservação de energia, Ensino de física.

A variation of the well-known drop of a neodymium - iron - boron magnet inside a tube of non-magnetic conductive material is presented in this work; the magnet removed from a movement mechanism of the recording and reading arm of a hard disk is placed to slide through an aluminium ramp placed close to the vertical. This configuration has the great advantage of being able to be seen by a (eventually) large audience; energy transformations are simple enough to be dealt with in medium level school physics courses. The treatment given to this teaching activity, appropriate to the medium level of teaching Physics, or even introductory higher education, involves the exploration of principles related to energy conservation.

Keywords: Induced currents, Energy conservation, Physics teaching.

\section{Introdução}

Coloque um imã de Neodímio - Ferro - Boro, $\left(\mathrm{Ne}_{2}-\mathrm{Fe}_{14^{-}}\right.$ B) retirado do mecanismo do braço de leitura de um disco rígido, sobre uma rampa de alumínio, como a da figura 11 à esquerda, e libere-o para descê-la. Essa rampa tem uma grande inclinação (a da figura 1 faz $15^{\circ} \mathrm{com}$ a vertical), e mesmo assim, o imã desliza rampa abaixo com uma velocidade surpreendentemente baixa (Veja o vídeo desse movimento em https://youtu.be/I29sVlj 09Bs). Inicialmente, discutiremos brevemente o porquê dessa descida assim tão lenta, do ponto de vista das correntes induzidas, com base em referências bibliográficas, dado que esse é um tema já explorado. O imã retirado do mecanismo de leitura de um disco rígido é sugerido aqui pelo fato de deslizar pela rampa sem rotação e permitindo, adicionalmente, uma grande interação eletromagnética entre o imã e a rampa de alumínio. Imãs de $\mathrm{Ne}_{2}-\mathrm{Fe}_{14}$-B, adquiridos no mercado, são encontrados em diferentes formas; quando em formato de esferas ou cilindros; tendem a descer planos inclinados em rotação, tornando assim a exploração das transformações de energia, proposta central desse trabalho, de difícil aplicação

*Endereço de correspondência: fcatelli@ucs.br no nível médio de ensino de física, ao qual se destina esse artigo. Imãs comerciais de formato mais achatado, sejam eles retangulares, ou discos finos, também produzirão resultados similares aos aqui apontados com o uso de imãs retirados de discos rígidos.

Num segundo momento, discutiremos as transformações de energia que ocorrem durante a descida, assunto esse não abordado, pelo menos não em detalhe, nas referências aqui apresentadas. Outro aspecto que introduz uma originalidade adicional ao trabalho, refere-se ao fato de a descida do imã poder ser acompanhada por uma grande audiência; o imã descendo no interior de um tubo de alumínio, como é o caso na maior parte das referências apresentadas, só pode ser visto por uma pessoa por vez, e é difícil de capturar em vídeo o movimento. Já a descida por uma rampa (como apresentado na figura 1 pode, adicionalmente, ser fotografada em múltipla exposição (figura 1) ou filmada, para posterior vídeo análise. Artigos de imãs cilíndricos descendo rampas são referidos na literatura [1], e podem, bem entendido, ser acompanhados por uma grande audiência. Entretanto, a necessidade de considerar o rolamento desses imãs, tornam esses trabalhos menos indicados para o ensino da física em nível médio, por envolverem conceitos como o momento de inércia. 

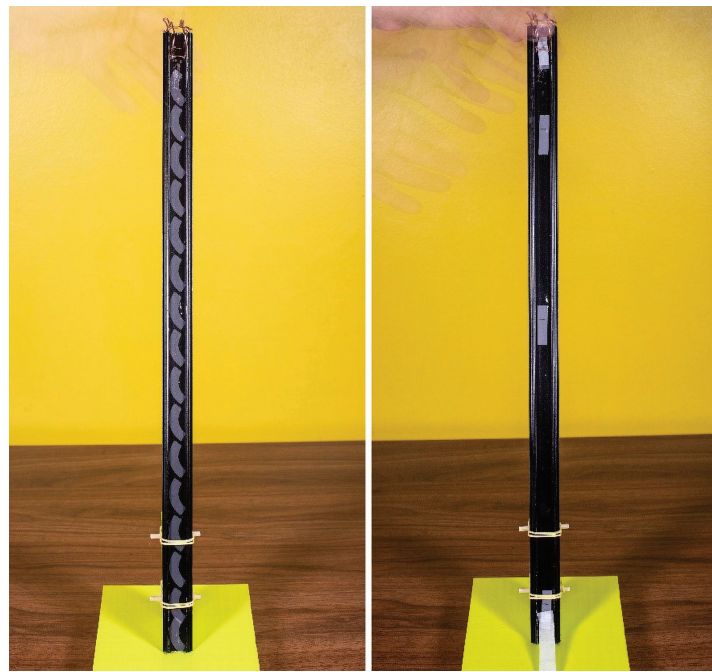

Figura 1: À esquerda, o imã de neodímio, retirado do mecanismo de um braço de leitura de um HD, desce uma rampa de alumínio quase vertical $\left(15^{\circ} \mathrm{com}\right.$ a vertical, pintada de preto). À direita, uma pequena lâmina retangular de ferro, não magnética, desce a mesma rampa. $\mathrm{Na}$ imagem à esquerda, o tempo de descida chega a quase $4 \mathrm{~s}$, numa rampa de $50,5 \mathrm{~cm}$ de comprimento. À direita, o tempo de descida chega a menos de $0,5 \mathrm{~s}$, uma queda quase livre.

Outra exploração bastante conhecida trata da "frenagem" de um pêndulo, feito de uma lâmina de alumínio, ao passar próximo a um imã. Aqui também, a restrição apontada no parágrafo anterior é válida: alguns dos conceitos de física necessários para uma abordagem preliminar das transformações de energia envolvidas não fazem parte desse nível de ensino. A mesma argumentação, associada à adequação da exploração das transformações de energia em nível médio, seria aplicável às demonstrações associadas aos assim chamados "trens magnéticos" $\sqrt{1}$ A peculiaridade, nesse último caso, é a de que a instrumentação necessária para a execução de uma atividade experimental se tornaria excessivamente complexa; veja-se a dificuldade associada, por exemplo, à medição da corrente fornecida pela pilha, enquanto o trem se move.

\section{O que Torna o Movimento do Imã tão Lento?}

Se, na mesma rampa, for colocada uma peça retangular metálica, de dimensões comparáveis às do imã, mas não magnética, ela descerá a rampa praticamente em queda livre, como pode ser percebido na imagem da direita da figura 1, na qual os disparos de flash ocorreram à taxa de 10 por segundo. Como, perguntam os estudantes que entram pela primeira vez em contato com esse

1 Há muitas propostas de construção e exploração de trens magnéticos na WEB. Veja, por exemplo, https://www.youtub e.com/watch?v=eTjrWF8sOHw estranho fenômeno, a descida é tão lenta no caso do imã, se esse não é atraído pelo alumínio? A resposta, dada aqui de modo bastante sucinto, por já ter sido explorada em detalhe em diversos outros trabalhos [1 [5], é a de que um imã, em movimento nas proximidades de um condutor, induz nele correntes, também conhecidas como "correntes de Foucault". Nesse trabalho, a atenção estará voltada à parcela de energia mecânica que é dominantemente transformada em energia elétrica, a qual imediatamente se transforma em energia térmica. As correntes induzidas surgem a partir da presença de uma força eletromotriz induzida (FEM induzida), decorrente de uma variação do fluxo magnético no tempo,

$$
\varepsilon=-\frac{\Delta \Phi_{m}}{\Delta t}
$$

onde $\epsilon$ é a FEM induzida, $\Delta \Phi_{m}$ é a variação do fluxo magnético (escrita numa notação formal acessível ao nível médio de ensino de física, ao qual esse trabalho é voltado), sendo que esse fluxo magnético é (simplificadamente) o produto da componente perpendicular do campo magnético por uma determinada área $\left(\Delta \Phi_{m}=\right.$ $\left.B_{\perp}^{*} A\right)$. Os leitores reconhecerão na expressão (1) a lei da indução, de Faraday [6].

Uma mera análise visual da imagem à esquerda na figura 1 mostra que a velocidade de descida do imã é constante: o leitor perceberá que o espaçamento entre as sucessivas imagens é uniforme. Na figura 2 a seguir, é apresentado, à esquerda, um gráfico da posição X (ao longo da rampa) versus o tempo para esse movimento, no qual fica confirmada a alegada constância da velocidade. Os dados foram retirados da imagem à esquerda da figura 1) aberta no Paint@) (um software gráfico do Windows), da seguinte maneira: ao posicionar o cursor num determinado ponto da imagem, aparecerão na tela, abaixo, à esquerda, as coordenadas daquele pixel. Dessa forma, é possível quantificar as sucessivas posições do imã, em pixels. A conversão para outra unidade de medida é simples: o comprimento total da rampa (ou qualquer outro referencial na foto cujas dimensões sejam conhecidas) é associado ao seu comprimento, em $\mathrm{cm}$, por exemplo: 5232 pixéis $\rightarrow 50,5 \mathrm{~cm}$ (esses são dados retirados da montagem mostrada na fig. 1). Outra providência a ser tomada é a de atribuir o valor zero à medida da primeira posição do imã na rampa, no início da descida. Dessa forma, o valor em pixels desse primeiro ponto é subtraído do valor que lhe corresponde e de todas as demais leituras.

Uma palavra adicional sobre a obtenção da imagem estroboscópica aqui apresentada: enquanto o imã desce a rampa, um flash fotográfico, ajustado (nesse caso) para quatro disparos por segundo ilumina periodicamente a descida, enquanto a câmara que captura a foto fica com seu obturador aberto. A tomada da foto de múltipla exposição se faz em um ambiente medianamente escurecido, onde a luz predominante é a do flash. O contraste entre o imã, que tem a sua face voltada para fora 


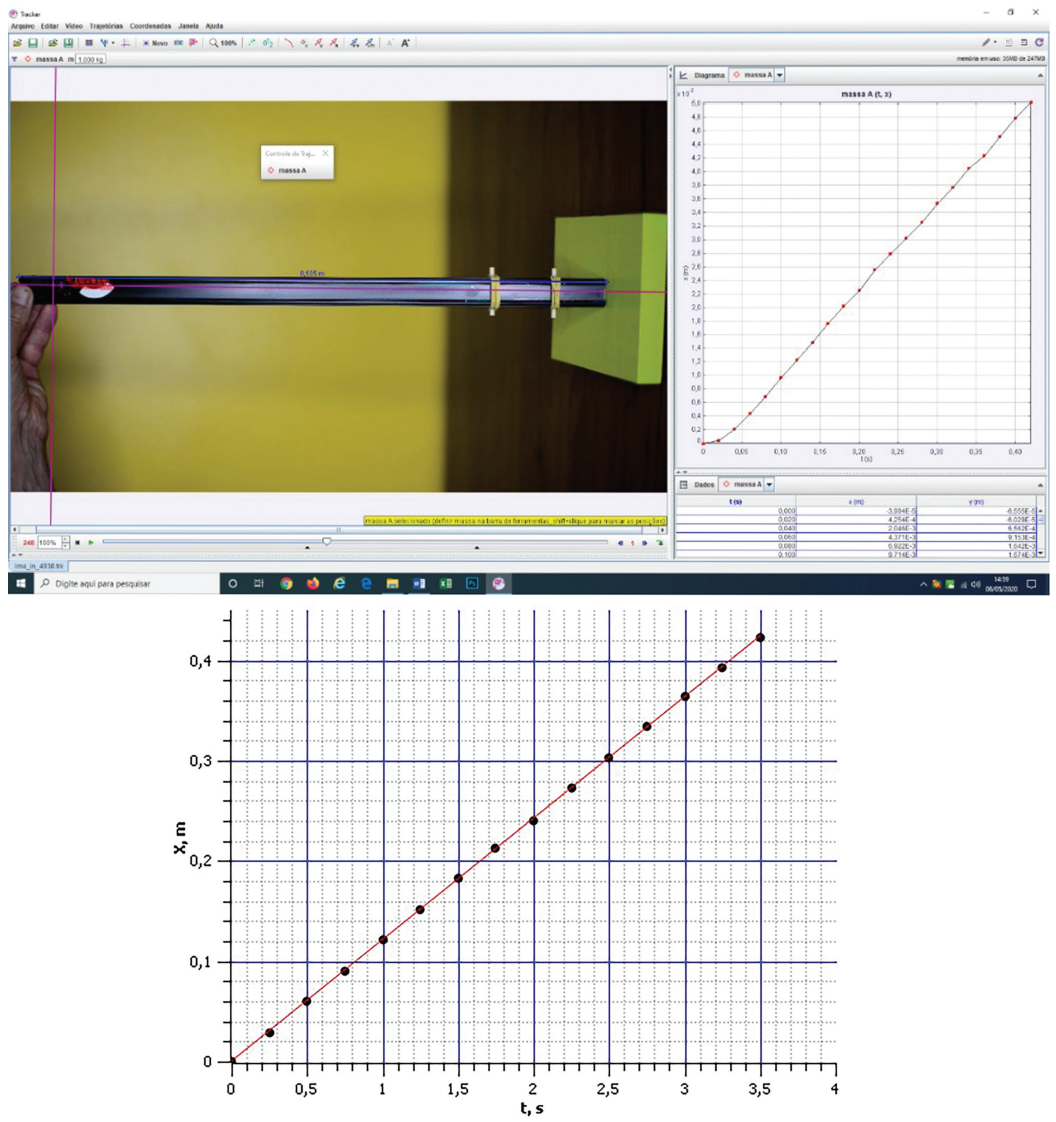

Figura 2: (Imagem superior) O início do movimento de descida do imã. O leitor perceberá que, a partir do quarto ponto, aproximadamente, o movimento já assume um movimento constante. Isso ocorre a partir de uma distância percorrida de $\approx 0,2 \mathrm{~cm}$, ou depois de um tempo de $\approx 0,04 \mathrm{~s}$, valores esses obtidos de forma estimativa. (Imagem inferior) $\mathrm{O}$ gráfico da distância versus o tempo, retirado da imagem à esquerda, na figura 1 . conforme descrito no texto.

da rampa revestida com um papel adesivo branco, é bastante visível se a rampa for pintada com, por exemplo, tinta spray preta fosca. Para essa imagem, foram feitos 16 disparos de flash, à razão de 4 por segundo; o obturador da câmara ficou aberto por 4 segundos. O número de disparos e a frequência destes são ajustados no flash. A intensidade do flash foi regulada para 1/128; é uma regulagem na qual o tempo de duração do disparo é da ordem de uma fração de milésimo de segundo, o que garante imagens nítidas, mesmo num movimento rápido como o dos quadros finais da foto da direita, na figura 1 .

O recurso de programar múltiplos disparos de flash pode ser encontrado em câmaras fotográficas, em geral de uso profissional, ou em alguns modelos de flashes, de uso também profissional.

No gráfico apresentado à direita da imagem superior da figura 2 também da velocidade $\mathrm{X}$ versus o tempo, é possível ver com mais detalhe o início do movimento, com dados obtidos de uma vídeoanálise do movimento, com 50 quadros por segundo. Aqui, constata-se que a distância cresce de forma não linear nos primeiros quatro pontos (aproximadamente), para em seguida estabilizarse com um crescimento constante. Os pontos foram

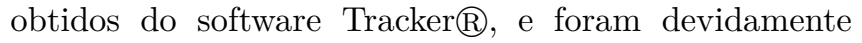

calibrados através da opção "bastão de calibração". O recurso da vídeoanálise é muito mais acessível do que a foto estroboscópica, dado que o software Trackerß] [7] é de acesso gratuito, e a filmagem pode ser feita a partir de um telefone celular. É aconselhável fixar o telefone celular (ou a câmara) a um tripé, de modo a evitar movimentos durante o percurso. O gráfico da parte inferior da figura 2 obtido da foto de múltipla exposição, atesta que o movimento é predominantemente uniforme, na maior parte da descida; a regressão linear dos dados dá uma velocidade de $0,121 \mathrm{~m} / \mathrm{s}$, e o coeficiente de determinação $r^{2}$ é 0,99995 .

\section{As Principais Forças Envolvidas na Descida do Imã}

Conforme já estabelecido (experimentalmente) mais acima nesse texto, o fato de a velocidade de descida do imã ser constante em praticamente todo o percurso implica numa força resultante nula: se há força resultante, há aceleração, e se há aceleração (num movimento em linha reta), o módulo da velocidade não pode ser constante. Assim, a força que "compensa" a componente da gravidade paralela à rampa é chamada aqui de 


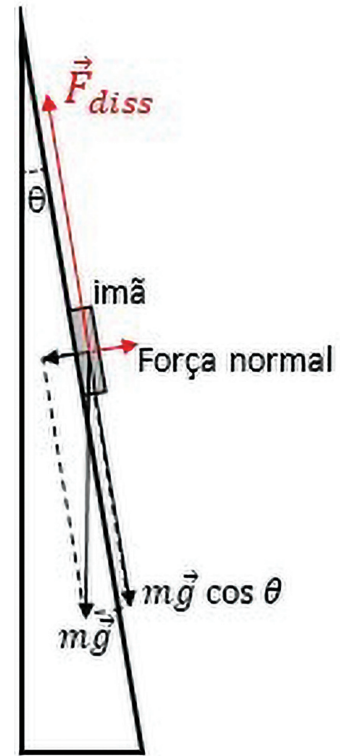

Figura 3: Vista lateral esquemática do imã descendo a rampa. Como argumentado no texto, a velocidade de descida do imã é $\approx$ constante, na maior parte do percurso. Então, a força resultante sobre o imã deve ser nula, o que faz com que a componente da força peso paralela à rampa $(m \vec{g} \cos \theta)$ seja igual e oposta à soma das forças dissipativas $\left(\vec{F}_{\text {diss }}\right.$, na figura). Como será argumentado mais adiante, essas forças dissipativas estarão associadas ao aquecimento da rampa de alumínio.

" $F_{\text {diss }}$ ", que engloba todas as forças dissipativas que se fazem presentes, em especial a força magnética, que é assim qualificada pelo fato de as correntes induzidas produzirem o aquecimento da rampa de alumínio por efeito Joule (figura 3).

Como essa força dissipativa é igual em módulo à componente da força peso paralela à rampa, podemos escrever que

$$
F_{\text {diss }}=m g \cos \theta
$$

Por fim, a componente perpendicular da força da gravidade que age sobre o imã, $m g$ sen $\theta$, provoca uma força de reação, uma força normal $F_{N}$, da rampa sobre o imã, que possui esse mesmo valor, também em módulo:

$$
F_{N}=m g \sin \theta
$$

\section{As Transformações de Energia na Descida do Imã}

Dada a constância da velocidade, a energia cinética será, ela também, constante, na maior parte do percurso. Para sermos um pouco mais precisos, a energia cinética cresce de zero até a energia cinética que corresponde à velocidade final $(12,1 \mathrm{~cm} / \mathrm{s})$ ao longo (aproximadamente) dos primeiros $0,04 \mathrm{~s}$, para depois permanecer constante até o final da descida, como pode ser aferido no gráfico imagem superior da figura 2. Esse intervalo de tempo para atingir a velocidade final (velocidade terminal) é consistente com a previsão que pode ser feita a partir da equação (2) da referência [1].

Para a análise do movimento com velocidade constante, foram consideradas as primeiras 15 imagens da foto de múltipla exposição da figura 1 (à esquerda); na última (a 16 $6^{\mathrm{a}}$ imagem), o disparo de flash ocorreu quando o imã já tinha tocado a base, e, portanto, não foi computado. Uma análise bastante plausível pode então ser feita, sendo ela válida para a quase totalidade do movimento: nas primeiras frações de segundo, o imã adquire, às custas de uma (pequena) diminuição da energia potencial, uma energia cinética, que logo deixa de crescer. Nesse mesmo percurso, uma outra parcela (também muito pequena) de energia potencial é transformada em energia térmica, conforme será explanado a seguir.

O que ocorre, do ponto de vista das transformações de energia, a partir do momento em que a velocidade e, consequentemente, a energia cinética, passa a ser constante? Praticamente todos os livros texto de Física tratam do tema "conservação de energia". Sugerimos uma consulta à referência [8], por julgá-la bastante adequada ao nível médio, para o qual está preferencialmente dirigido esse artigo. Como o imã segue perdendo altura, a taxa com a qual a energia potencial vai decrescendo no tempo torna-se idêntica à taxa com a qual a energia térmica vai surgindo, predominantemente, no trilho de alumínio. O surgimento dessa energia térmica deve-se na sua maior parte às correntes induzidas, como argumentaremos a seguir, mas também há uma parcela que é devida ao atrito. Em termos formais, de maneira aproximada, teríamos as seguintes relações, estruturadas a partir do princípio pelo qual a soma de todas as formas de energia, no início do movimento, é idêntica à soma de todas as formas de energia, no final do movimento:

$$
m g X \cos \theta=\frac{1}{2} m v^{2}+(\text { energia térmica no alumínio })
$$

$\mathrm{Na}$ expressão acima, o primeiro termo à esquerda corresponde à energia potencial, na qual $m$ é a massa do imã, $X$ é a distância ao longo da rampa percorrida pelo centro de massa do imã, contando como ponto inicial o centro de massa deste na primeira imagem e como ponto final, $X=0$, o centro de massa da última imagem considerada (a $15^{\mathrm{a}}$ ); $\theta$ é o ângulo da rampa com a vertical. A energia cinética inicial é nula (o imã parte do repouso), e a energia térmica também não aparece à esquerda da igualdade, por não ter, ainda, ocorrido movimento.

É importante ressaltar que as correntes induzidas produzirão o aquecimento do alumínio por efeito Joule. $\mathrm{O}$ aquecimento do alumínio, tanto o que tem origem nas correntes induzidas, quanto o que está associado ao atrito, são formas de aquecimento adiabático, não envolvendo trocas de calor. Essas trocas ocorrerão quando a região aquecida adiabaticamente trocar energia com o 
ambiente, esse a uma temperatura (agora) mais baixa.

$\mathrm{Na}$ parte final do movimento, o termo correspondente à energia potencial é nulo (para o referencial escolhido, no qual a altura zero do centro de massa é a que corresponde à última imagem considerada). O segundo termo corresponde à energia cinética, e o terceiro, às energias térmicas. A massa do imã empregado é de $3,2 \mathrm{~g}(0,0032 \mathrm{~kg})$ e a distância $X$ percorrida pelo centro de massa do imã, nas 15 primeiras imagens, 0,423 m. Tomamos a aceleração da gravidade como $9,8 \mathrm{~m} / \mathrm{s}^{2}$; o ângulo $\theta$, como já referido, vale $15^{\circ}$. A velocidade (constante) do imã é aproximadamente $12,1 \mathrm{~cm} / \mathrm{s}$. No início do movimento, a energia total corresponde à energia potencial, e com os valores numéricos acima, chegamos a $m g X \cos \theta \approx 0,0128$ J, ou 12,8 mJ. Já a energia cinética, no final do movimento, leva a $\frac{1}{2} m v^{2} \approx 2,3 \times 10^{-5} \mathrm{~J}$, ou 0,023 mJ. Essa energia cinética corresponde apenas a, aproximadamente, $0,18 \%$ da energia total disponível no início do movimento.

A conclusão que se põe é a de que, então, as energias térmicas são (muito) aproximadamente iguais à energia total disponível no início do movimento, a energia potencial. Um gráfico, que relaciona as diferentes energias envolvidas (energia total, energia cinética, energia potencial e energia térmica) pode ser visto a seguir, na figura 4

A próxima questão que poderia ser colocada é: visto que essas energias aparecem sob duas formas, energia térmica resultante do atrito do imã com a rampa, e energia térmica resultante das correntes induzidas, qual seria a forma predominante, a correspondente ao atrito, ou a correspondente às correntes induzidas? (Desconsideramos aqui a resistência do ar, dado que

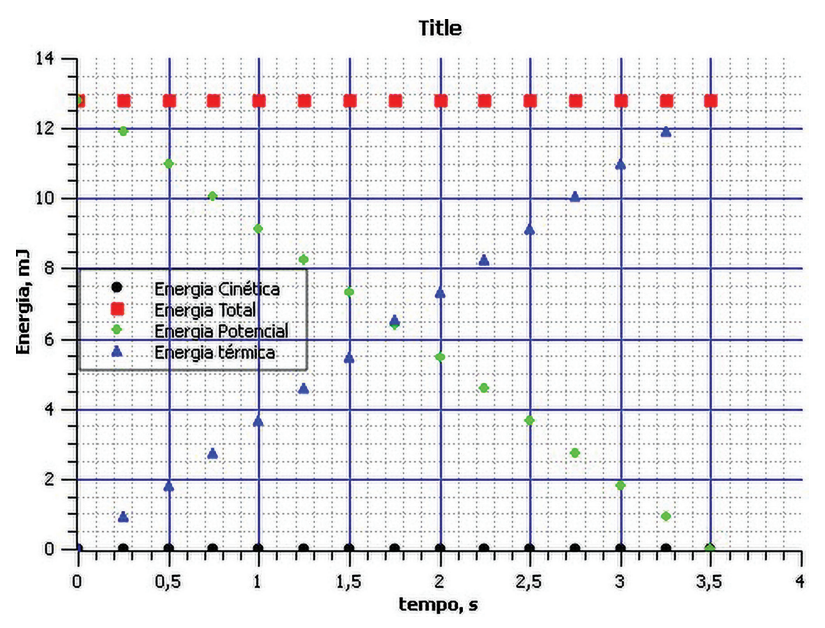

Figura 4: Variação das diferentes energias envolvidas na descida do imã, em $\mathrm{mJ}$, em função do tempo. A energia cinética (em preto) é da ordem $0,18 \%$ da energia total, que aparece em vermelho. A variação da energia potencial (que aparece em verde) é muito aproximadamente a mesma taxa de acréscimo da energia térmica (em azul), consequência das correntes induzidas (predominantemente) e da fricção do imã com a rampa. o movimento é muito lento). É relativamente simples quantificar, pelo menos de forma aproximada, a primeira delas, se estivermos de posse do coeficiente de atrito do imã com a rampa.

Um modo experimental de estimá-lo consiste em arrastar, com velocidade aproximadamente constante, o imã sobre a rampa, por meio de um dinamômetro, e com isso medir a força de atrito. Mas esse procedimento não é plausível, dado que induziríamos correntes no alumínio da rampa, e então precisamos chegar a esse coeficiente de atrito arrastando o imã sobre uma superfície não condutora, mas similar à superfície da rampa, em termos de superfícies de contato. Como estamos interessados em ordens de grandeza, e não em valores acurados, a medição da força de atrito (com o intuito de chegar ao coeficiente de atrito) foi realizada numa superfície plana (uma folha de papel de impressora). Com uma força de atrito, medida experimentalmente, de $11,8 \mathrm{mN}$, e com a massa do imã dada acima, 0,0032 kg, chega-se ao atrito cinético a partir da expressão

$$
F_{a t, k}=\mu m g
$$

onde $F_{a t, k}$ é a força de atrito cinético, $\mu$ é o coeficiente de atrito cinético, e $m g$, a força normal (igual ao peso, em módulo, dado que a superfície é plana e horizontal). Chega-se assim a um coeficiente de atrito cinético $\mu=0,38$.

Supondo que seja esse o coeficiente de atrito entre a rampa e o imã, podemos calcular a força de atrito nessas condições. O leitor notará, entretanto, que, como a rampa é inclinada, a força normal não será mais a força peso, e sim a componente da força peso perpendicular à rampa; veja o diagrama da figura 2 (A suposição de que o coeficiente de atrito é o mesmo pode, por certo, ser contestada. Mas como a busca é por uma ordem de grandeza, se o coeficiente de atrito for outro, ele certamente não será tão diferente, validando assim, pelo menos de forma aproximada, essa estimativa). Temos então:

$$
F_{a t, r a m p a}=\mu m g \sin \theta \approx 3,1 \times 10^{-3} \mathrm{~N}
$$

Por fim, o trabalho realizado pela força de atrito ao longo do percurso $(0,423 \mathrm{~m})$ corresponderá à energia que aparece sob forma de energia térmica, por conta do atrito:

$$
W_{f \text { atrito }}=F_{a t, \text { rampa }} * X=1,3 \times 10^{-3} \mathrm{~J}
$$

Se comparamos essa energia, 1,30 mJ, com a energia inicial, 12,8 mJ, vemos que ela corresponde a 10,2\% dessa última. Ou seja, 90\% (arredondando) correspondem à energia térmica oriunda das correntes induzidas. (O leitor lembrará que demonstramos experimentalmente que

$$
m g X \cos \theta \approx \text { energia térmica, }
$$

desprezando o termo referente à energia cinética, que é muito pequeno (ver equação 4). Nas conclusões, a seguir, 
será mencionada uma configuração (uma lanterna) na qual um imã se move linearmente para a frente e para trás no interior de um enrolamento de fio de cobre. Nessas condições, em vez de a corrente acabar por resultar em energia térmica na canaleta de alumínio (como é o caso nesse trabalho), ela poderá ser direcionada a uma bateria e (ou) acender uma lâmpada de LED.

Um último aspecto a ser considerado é o de que poderia existir uma componente da força magnética orientada perpendicularmente à rampa, o que aumentaria o atrito (se essa força apontasse para a rampa) ou o diminuiria (se a força apontasse para longe da rampa). Para verificar experimentalmente essas possibilidades, o imã foi suspenso por fios (como um pêndulo) e mantido em repouso na sua posição de equilíbrio; a rampa de alumínio, colocada numa canaleta de madeira, pela qual pudesse deslizar livremente, foi solta em queda livre, o mais próximo possível do imã, o que provocou um pequeno afastamento desse último da vertical, para longe da rampa. Então, é possível afirmar que a força de atrito, estimada acima, deve ser na prática ainda menor. Outra forma experimental de corroborar a afirmação segundo a qual um imã tende a se afastar de um condutor não magnético, quando há movimento relativo entre ambos, pode ser encontrada na referência [9].

\section{Conclusões}

Uma boa medida da pertinência de uma proposta didática investigativa, como é o caso da aqui apresentada, é o número e a qualidade das perguntas feitas pelos estudantes, ao interagirem com os - como dizíamos acima - estranhos fenômenos aqui apresentados. Uma das perguntas, feita por um estudante, foi mais ou menos a que segue: se praticamente toda a energia (90\%) que não é cinética se transforma em energia térmica, dá para perceber a rampa de alumínio aquecendo? Para responder a essa pergunta, será estimado o valor dessa energia, e será calculado o aumento de temperatura do alumínio da rampa, devido à energia térmica por ele recebida, oriundo das correntes induzidas. É uma conta simples de fazer. Inicialmente, a equação 4 nos diz, de forma aproximada, que $90 \%$ dos $12,8 \mathrm{~mJ}$ da energia potencial no início do movimento se transforma em energia térmica, a qual pode, também aproximadamente, ser associada às correntes induzidas. Da calorimetria, têm-se que o calor recebido por um sólido aumenta sua temperatura segundo a expressão

$$
Q=m c \Delta t
$$

A massa do trilho de alumínio é de $55 \mathrm{~g}$ (0,055 kg) e o calor específico, $921 \frac{\mathrm{J}}{\mathrm{kg} \mathrm{K}}$. Para o valor de Q, tomou-se $90 \%$ do valor da energia potencial, no início do movimento, consoante a argumentação desenvolvida mais acima. Chega-se assim a um acréscimo de temperatura $\Delta t$ de $2,3 \times 10^{-4} \mathrm{~K}$, ou 0,23 milésimos de grau Celsius (como é uma diferença de temperatura, pode ser expressa em ${ }^{\circ} \mathrm{C}$ ou $\mathrm{K}$, indiferentemente). $\mathrm{O}$ instrumental para detectar experimentalmente uma tal variação de temperatura não é - seguramente - simples de operacionalizar; tal acréscimo de temperatura seria impossível de perceber pelo tato.

Outra pergunta curiosa que surgiu dizia respeito à possibilidade de alimentar algum aparelho com as correntes produzidas. Um caminho didaticamente fértil para produzir uma resposta inicial à questão é o de calcular a taxa com a qual a energia potencial é parcialmente transformada em energia térmica. Tomando a parcela correspondente à dissipação de energia por correntes de induzidas, $90 \%$ de 12,8 mJ, e dividindo pelo tempo de descida, 3,5 s, chega-se a $3,3 \mathrm{~mW}$, ou 3,3 milésimos de watt. É de fato uma potência pequena. Mas, curiosamente, ela seria suficiente para alimentar, por exemplo, 16 calculadoras LCD de 0,0002 W (Casio N78®).

Imãs em movimento (linear) podem, afinal, produzir energias "aproveitáveis"? Essa questão surgiu da pergunta de um aluno a respeito da possibilidade de utilizar na prática tais energias. Uma geometria otimizada do movimento de um imã pode, sim, transformar energia mecânica em energia elétrica, que pode ser armazenada num acumulador de uma lanterna de LED; essa energia garantirá seu funcionamento por um certo tempo. Modelos comerciais de lanternas que operam segundo esse princípio podem ser encontrados no comércio informal; há um modelo no qual, ao sacudi-lo ao longo de seu comprimento, um imã cilíndrico de neodímio se deslocará, num movimento de vai e vem, por dentro de um enrolamento de fio, ao longo do corpo da lanterna. A energia produzida por algumas dezenas de sacudidas, acumulada no interior de uma pequena bateria interna, é suficiente para manter a lanterna acesa por algum tempo, da ordem de minutos. Reiterando o que foi dito mais acima: no caso de o imã se mover por dentro de um enrolamento de fio, em vez de as correntes induzidas resultarem em energia térmica (como foi o caso tratado nesse trabalho) a corrente induzida (no enrolamento) promoverá o acendimento da lâmpada de LED da lanterna e (ou) o carregamento de uma pequena bateria interna. A escolha de lanternas nas quais a energia do movimento de vai e vem resulta no acendimento da lâmpada se deu por uma razão didática: seu corpo é transparente, permitindo aos alunos a visualização do imã e seu movimento - linear - no interior de um enrolamento de fio, esse também visível. Certamente não são as lanternas nas quais a conversão de energia é a mais eficiente, há outros modelos nos quais a energia mecânica tem origem no giro de uma pequena manivela. Mas, nesses modelos, nem o imã nem o enrolamento de fio podem ser visualizados.

Por fim, destacamos que a intensão aqui foi, explicitamente, a de explorar as transformações de energia, usando para isso um tratamento matemático acessível aos estudantes do ensino médio, e não "demonstrar" de forma a mais precisa possível a exatidão dos valores 
obtidos. Por isso, não foram apresentadas incertezas nos cálculos. O único dado numérico nessa direção foi o fator $\mathrm{r}^{2}$, na regressão linear referente ao gráfico da figura 2 (imagem inferior), por ele atestar que, de fato, a descida do imã se dá com velocidade constante, o que se constituiu no argumento de partida para as argumentações que se seguiram.

O desenho desta atividade experimental foi feito com base na possibilidade de explorar ao máximo os conceitos que fazem parte do universo da física no ensino médio. Essa restrição afastou, como argumentado brevemente na introdução, atividades que envolvessem o movimento rotacional de objetos extensos, tais como o rolamento de imãs cilíndricos, ou o movimento de pêndulos físicos.

\section{Agradecimentos}

Aos revisores da RBEF, pela cuidadosa e competente revisão realizada.

\section{Referências}

[1] F.L Silveira e M.C. Varialle, Rev. Bras. Ens. Fís. 31, 4303 (2009).

[2] F. Catelli, Cad. Cat. Ens. de Fís. 16, 344 (1999).

[3] R.M. Szmoski, A. Doff, V.M. Lenart, S.K. Schwiderke e L.V.G. Fachini, Rev. Bras. Ens. Fís. 40, e1505 (2018).

[4] F.L. Silveira, Y. Levin e F.B. Rizzato, Cad. Bras. Ens. Fis. 24, 295 (2007).

[5] F.L. Silveira, Y. Levin e F.B. Rizzato, Am. Journal Phys. 74, 815 (2006).

[6] J. Walker, Fundamentos de Física (LTC, Rio de Janeiro, 2016) v. 3.

[7] Trackerß: https://physlets.org/tracker/, acessado em nov. 2020.

[8] P. Hewitt, Física Conceitual (Bookman, Porto Alegre, 2015).

[9] A.G. Paula e D.M. Vianna, Fis. na Esc. 8, 35 (2007). 